\title{
Rete middle cerebral artery: a rare variant
}

\section{Artéria cerebral média rete: uma variante rara}

Leonardo DEUS-SILVA ${ }^{1,2}$, Livia de OLIVEIRA², Luiz Gustavo de Abreu MATTOS², André Luís Nunes Albano de MENESES ${ }^{1,2}$

A 29-year-old female presenting migraine-like headaches was found to have irregular vessels resembling a moyamoya ${ }^{1}$ pattern involving the right middle cerebral artery (MCA). A digital cerebral angiography revealed the absence of a normal right $\mathrm{M} 1$ segment, with a tangle of serpiginous vessels connecting the carotid termination to a normal distal M1 (Figure 1). This structure is different from a moyamoya pattern and is likely related to the persistence of a fetal arterial network that eventually became the MCA main trunk ${ }^{2}$ (Figures 2 to 4). This rare, so-called rete MCA pattern is a normal variant and should be recognized as such to avoid unnecessary interventions ${ }^{3}$.

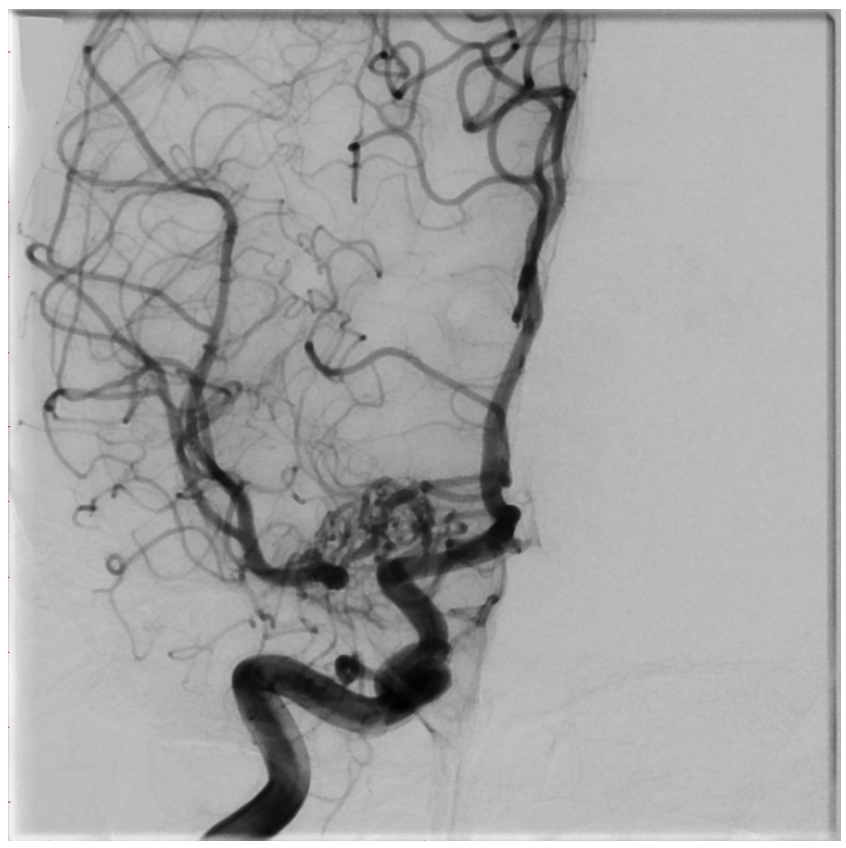

Figure 1. Right internal carotid angiogram showing the absence of a normal middle cerebral artery with a rete pattern of vessels connecting the carotid termination to a normal distal M1.

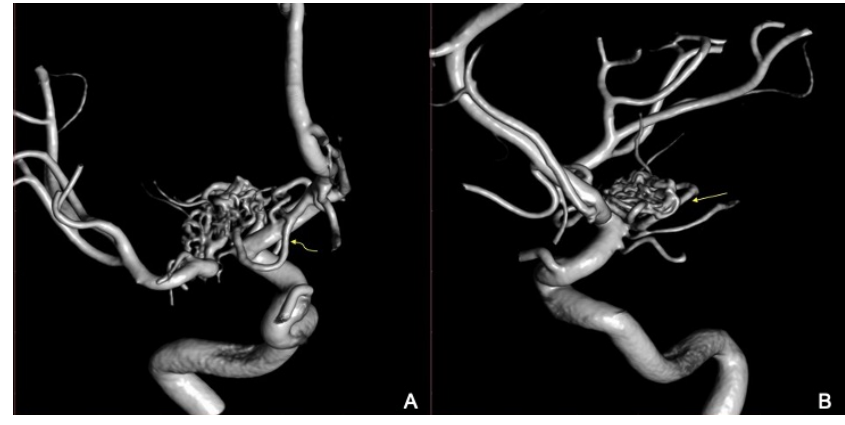

Figure 2. (A) 3D-rendered angiographic image in frontal view demonstrating contributions from the anterior cerebral artery (curved arrow) to the tangle of vessels reconstituting the distal M1 segment. (B) Lateral view of the same 3D image indicating the contribution of the anterior choroidal artery complex to the distal M1.

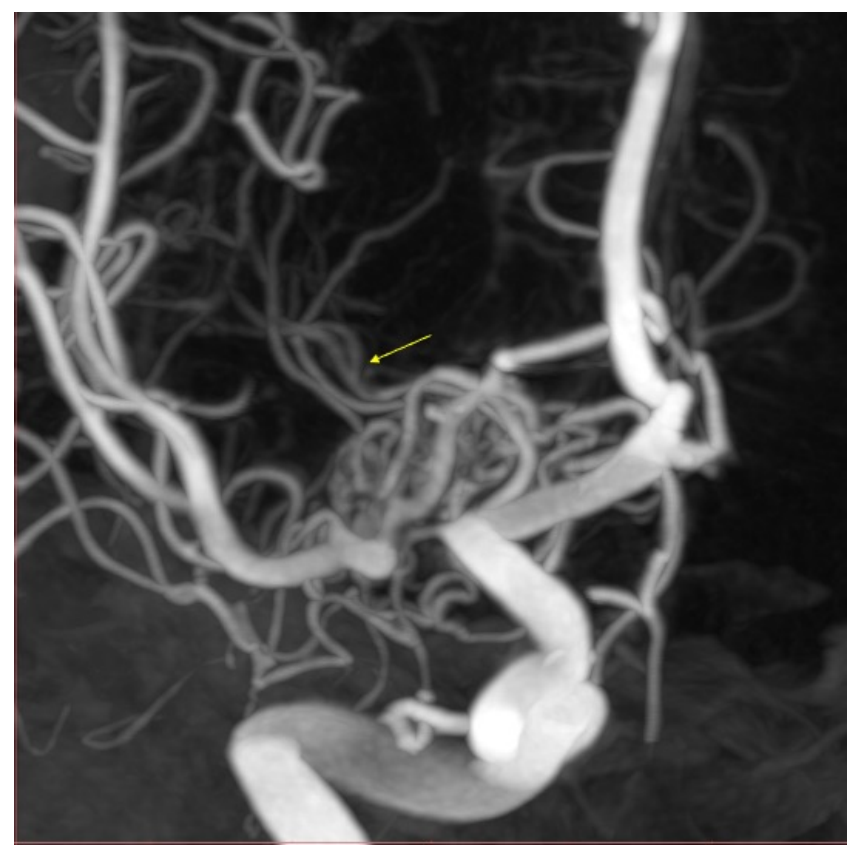

Figure 3. Multiplanar reconstruction of rotational angiography showing the presence of lenticulostriate arteries (arrow) arising from the anomalous proximal rete middle cerebral artery.

1 Universidade Estadual de Campinas, Hospital de Clínicas, Departamento de Radiologia, Seção de Neurorradiologia Intervencionista, Campinas SP, Brazil. ${ }^{2}$ Pontifícia Universidade Católica de Campinas, Hospital Celso Pierro, Neurorradiologia Intervencionista e Neurocirurgia Endovascular, Campinas SP, Brazil. Leonardo DEUS-SILVA (D) https://orcid.org/0000-0003-3775-401X; Livia de OLIVEIRA (D) https://orcid.org/0000-0002-9461-0461; Luiz Gustavo de Abreu MATTOS (iD) https://orcid.org/0000-0002-3386-7597;André Luís Nunes Albano de MENESES (iD) https://orcid.org/0000-0002-7574-4966

Correspondence: Leonardo Deus-Silva; E-mail: cerebrovascular@gmail.com

Conflict of interest: There is no conflict of interest to declare.

Received on July 20, 2020; Accepted on August 12, 2020. 


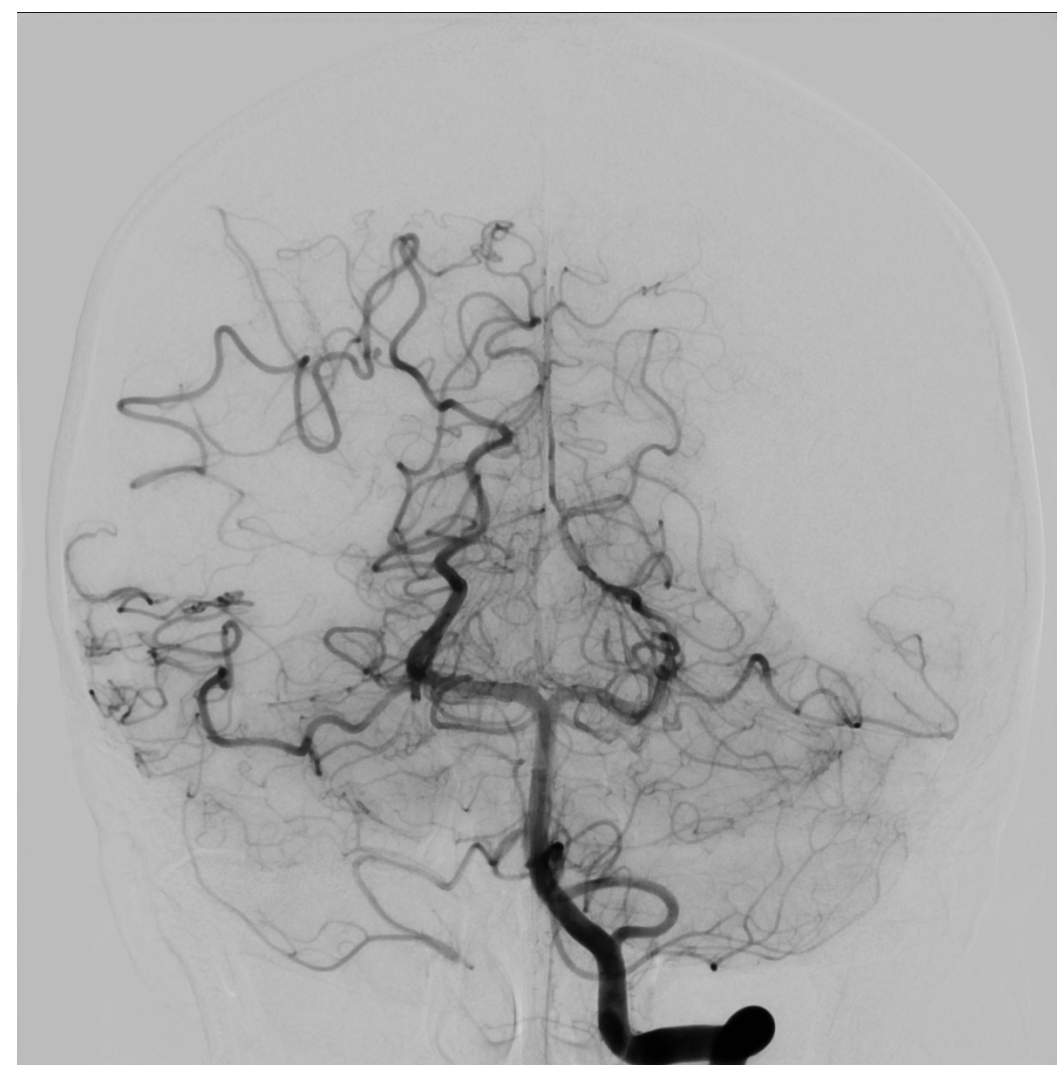

Figure 4. Frontal view of a vertebrobasilar angiogram demonstrating pial collaterals contributing to temporal and parietal vascular territories.

\section{References}

1. Scott RM, Smith ER. Moyamoya disease and moyamoya syndrome. N Engl J Med. 2009 Mar;360(12):1226-37. https://doi.org/10.1056/ NEJMra0804622

2. Cho KC, Kim JJ, Jang CK, Hong CK, Joo JY, Kim YB. Rete middle cerebral artery anomalies: a unifying name, case series, and literature review. J Neurosurg. 2018 Aug;131(2):453-61. https://doi. org/10.3171/2018.2.JNS1832

3. Colombo E, Brinjikji W, Klaas J, Lanzino G. Teaching Neurolmages: Rete-like middle cerebral artery. Neurology. 2019 Nov;93(20):e1919-20. https://doi.org/10.1212/WNL.0000000000008480 